\title{
Sustainable production in circular economy: aerogel upscaling production
}

\author{
Handojo Djati Utomo ${ }^{1}\left(\mathbb{D} \cdot\right.$ Xiaodong $\mathrm{Li}^{2} \cdot$ Eng Tak Jonathan $\mathrm{Ng}^{3}$
}

Received: 31 May 2021 / Accepted: 17 January 2022 / Published online: 25 January 2022

(c) The Author(s), under exclusive licence to Springer-Verlag GmbH Germany, part of Springer Nature 2022

\section{Introduction}

Circular Economy (CE) has become an economic imperative more than ever, compounded with many pressing factors such as game-changing and world-changing phenomena that have changed the industrial landscape. Among these factors, Industry 4.0 revolution (de Sousa Jabbour et al. 2018), environmental/resource impact, and social and regulatory pressures. There are only so much of resources at human's disposal in the current stage, making a paradigm shift from linear to circular the sustainable way to reconcile with the nature (Michelinia et al. 2017). This far-reaching trend has resulted in many countries, including Singapore, setting zero-waste masterplan as one of its key priorities (NEA 2020). This paper explores the green journey that the institution, Singapore Polytechnic, has taken from concept design to the development of its green masterplan to its evolution and establishment of focus on green technology research, and in particular, the upscaling of recycling of incinerator ash to aerogel technology.

Responsible Editor: Philippe Garrigues

Handojo Djati Utomo

han@sp.edu.sg

Xiaodong Li

Li_Xiaodong@sp.edu.sg

Eng Tak Jonathan $\mathrm{Ng}$ jonathan_NG@sp.edu.sg

1 School of Architecture \& the Built Environment, Singapore Polytechnic, Singapore 139651, Singapore

2 Advanced Materials Technology Centre, Singapore Polytechnic, Singapore 139651, Singapore

3 Technology, Innovation and Enterprise, Singapore Polytechnic, Singapore 139651, Singapore

\section{Evolution in sustainable research initiative}

The issue of climate change is not new and had emerged as early as 1988 with the establishment of the Intergovernmental Panel on Climate Change (IPCC) by the World Meteorological Organization (WMO) and the United Nations Environment Programme (UNEP) (IPCC 2008). For the institution, the early commitment to green has been deeply rooted and embodied in the institution's green pledge and exemplified in its campus in a garden philosophy (Singapore Polytechnic 2014). That culture had permeated to its teaching, learning, and research with the key green technology development activities taking place in its various schools, such as the waste recycling process technology developed jointly by the School of Architecture and the Built Environment $(\mathrm{ABE})$ and the department for technology, innovation and enterprise (TIE).

From its early days as the first polytechnic in Singapore, it has been working closely with the government to train and arm the workforce with the skills needed for the country's economic growth. As the pace of globalization accelerated in the 1980s to 1990s, the strategic policy was implemented to strengthen and drive towards becoming an innovation economy (The Strait Times 2017). It was with this strategy that led to the setting up of research and innovation centers in the local Institutes of Higher Learning (IHL) such as Singapore Polytechnic.

The earlier phase of development was focused on building of basic scientific research projects to develop the capabilities of the teaching staff with the help of researchers engaged to run the research centers known within the institution as the Technology Innovation Centres (or TIC in short). One of the new centers was the Advanced Materials Technology Centre (or AMTC in short) that started earlier key research into green specialty chemicals for various applications such as coatings for photovoltaics panels, buildings, and in manufacturing process. The AMTC has won awards such as the IES Prestigious Engineering Achievement Awards 
(IES 2014) for its technology innovation in green chemistry. The research has also yielded commercial success with a spin-off created with investment from the Singapore National Research Foundation funded Venture Capitalist (Nanowork Asia Pacific 2012). Today, the spin-off has received further rounds of funding with a subsidiary set up in China. This is very much in line with the strategic focus of the research center and at the National level, that was primarily to develop commercially viable intellectual properties to support the economic value creation and maturing its research and technology transfer capability, thus contributing towards building Singapore as an Intellectual Property Hub of the region.

With the launch of the government's zero-waste nation vision and setting the year 2019 as the year towards zero waste, the momentum was accelerated for the institution to consolidate the green technologies and charting its course for specific thematic technology research to build up its technological edge.

\section{Building platforms for research scale-up}

The center through the years has developed, among the other research areas, wastewater treatment and green-built environment materials as well with the aim of discovering greener, better, and cheaper solutions for the industry. The convergence of research areas amassing the different technological capabilities developed in green chemistry has resulted in closer alignment with the institution's School of Architecture and the Built Environment (ABE). The ABE was one of the oldest schools in the institution that at one point offered degree courses in 1965, before the decision to transfer the faculties of architecture and engineering to the University of Singapore in 1968. It was of no coincidence that the $\mathrm{ABE}$ as the first school to offer Built Environment (BE)-related course (Singapore Polytechnic 2018) was appointed as the sector coordinator for Building and Construction (MOE 2016) among the local polytechnics.

Apart from its extensive lesson-based pedagogy, as an applied learning institution, ABE has been through its practical learning platform allowing staff and students to engage in real-life and industry-relevant research projects to enable the application of knowledge and the use of skills to conceptualize, design, and develop industry-relevant solutions. These efforts have paid off well with its projects winning awards for several years in the Greenwave competitions (Sembcorp 2015).

Imbued with passions to pursue industry-relevant solutions for augmenting academic excellence, the ABE school's close collaboration with the AMTC (Singapore Polytehnic 2020) transformed the research ecosystem in the institution into a powerful twin-engine, which allows both the industry-relevant applied pedagogy and the applied scientific research's calibrated integration for the development of an innovative and curious mindset in its solution-minded graduates. Such kind of industry-research-infused methodology plays an instrumental role, among other strategic initiatives in achieving its mission of "Life-ready, Work-ready and World-ready."

With a school and TIC coming together, working on a calibrated approach, such collaborative platform allows for the systematic way of training of both staff and students through a structured framework that encompasses different work packages designed for supporting the industry. The work package themes are aggregated from the industry, representing the problem statements that require innovative solutions to either to increase the productivity or the development of specific capability to uplift the industry. In this way, not only does the industry benefit through the skilled and entrepreneurial workforce, such kind of industry engagement with companies also offers them the opportunity to transform their business with solutions designed to increase their competitiveness. The application of aerogel to multiple areas in BE materials was achieved for the waste to aerogel project through such platform (The Strait Times 2019).

\section{Manifesting the people-private-public partnership spirit}

The idea of the benefits of a closer partnership between the government and the community has been demonstrated in many places around the world with perhaps in the recent history of successful economic value generation through technology transfer and start-up creations in the USA from its government agency such as from the National Aeronautics and Space Administration (NASA), which evolved rapidly with the Bayh-Dole Act of 1980 in the USA (NASA 2012). The role of the close collaboration among key stakeholders is essential as argued by Hamilton (2003) to play a crucial role in success rate of generating economic value for the community. In Singapore, the relationship is manifested in a people-private-public (3Ps) partnership as first defined by the Singapore 21 Committee (1999).

The 3P partnership elevates the scale of collaboration allowing for a multiplier effect on the technology solutions developed by the institution to be proliferated at a quicker pace and to a broader range of target audience. In the waste to aerogel project for example, the partnership with the waste recycling association (CNA 2018) has yielded successful training and industry projects.

To close the waste loop, the cooperation and interwoven working network of the waste producers and waste recyclers are critical for the business case to work in the circular economy. As such, identifying the right partner to work with from the proof of concept to proof of value and ultimately an industry pilot scale-up is important. Therefore, through the institution's technology development strategy of "Seed," "Grow," and "Scale" phase of staging technology development projects, 
there is always an industrial collaborator involvement. While the seeding phase sees primarily laboratory experimental type of projects, most industrial collaborators will generally be more willing to take part in the "Grow" and "Scale" phase where the project is of a certain level of technology readiness level and the commercial potential is more apparent. Regardless of the stages however, the stake holders' engagement and viable business case continue to be the important factors for the ongoing waste- to- aerogel technology development journey.

\section{Circular economy: waste-to-aerogel development}

Silica aerogels are widely established as the world's lightest solid materials. Silica aerogel is composed of over $90 \%$ of air by its volume, with the remnant $10 \%$ consisting of silica nanoparticles which form an amorphous, cross-linked, threedimensional silica network (Lee et al. 2018). Due to such a high porosity value, silica aerogels are highly unique materials with a spectrum of fascinating properties: high specific surface area (500-1200 $\left.\mathrm{m}^{2} / \mathrm{g}\right)$; low refractive index (1-1.08); low density $\left(3-100 \mathrm{~kg} / \mathrm{m}^{3}\right.$, dependent on porosity of the aerogel); ultra-low dielectric constant $(\mathrm{k}=1.0-2.0)$, and low thermal conductivity $(0.003-0.02 \mathrm{~W} / \mathrm{mK}$ ) (Kow et al. 2014), (Gao et al. 2014). Because of such properties, silica aerogels are the optimal material for a multitude of applications and industries. Silica aerogels are being applied as thermal insulating materials (for refrigeration and construction use), acoustic barriers, absorbents, catalytic supports, and super capacitators (Kow et al. 2014), (Pan et al. 2017). However, the application of silica aerogel is hindered by its high price. The prices of aerogel powder vary from supplier to supplier of the product. Moreover, depending on the quality of the product, the price may differ as well. Active Aerogel's Aerogel beads (Silfiller) is priced at 35 Euros for $1 \mathrm{~L}$ volume; however, Cabot Corporation's silica aerogel (Enova Aerogel IC3100 Particles) is priced at $\$ 68$ for $1 \mathrm{~L}$. The Enova Aerogel comes in different particle sizes, ranging from ultrafine to coarse. Its cheaper counterpart, the Lumira aerogel particles, is priced at $\$ 55$ for $950 \mathrm{cc}(0.95 \mathrm{~L})$. And this price is much higher than that is affordable by the building industries. As such, demand for a faster and more costeffective production of silica aerogel is steadily increasing, spurring further research and studies to accomplish this goal.

In this work, the researchers found that there was a considerable silica content in the incineration ashes which could be considered as a cheap source of raw material for fabrication of silica aerogel. The results also proved that incineration bottom ash was a suitable raw material for the fabrication of the silica aerogel.

\section{Methodology}

Silica aerogel was fabricated from the incineration ashes by two steps; the details were described in our previous work (Lu et al. 2018). The incineration ashes were received from Sembcorp Industries (Singapore). The fabrication process of aerogel from incineration ashes is shown in Fig. 1 and
Fig. 1 Process of aerogel prepared with fly ash and bottom ash
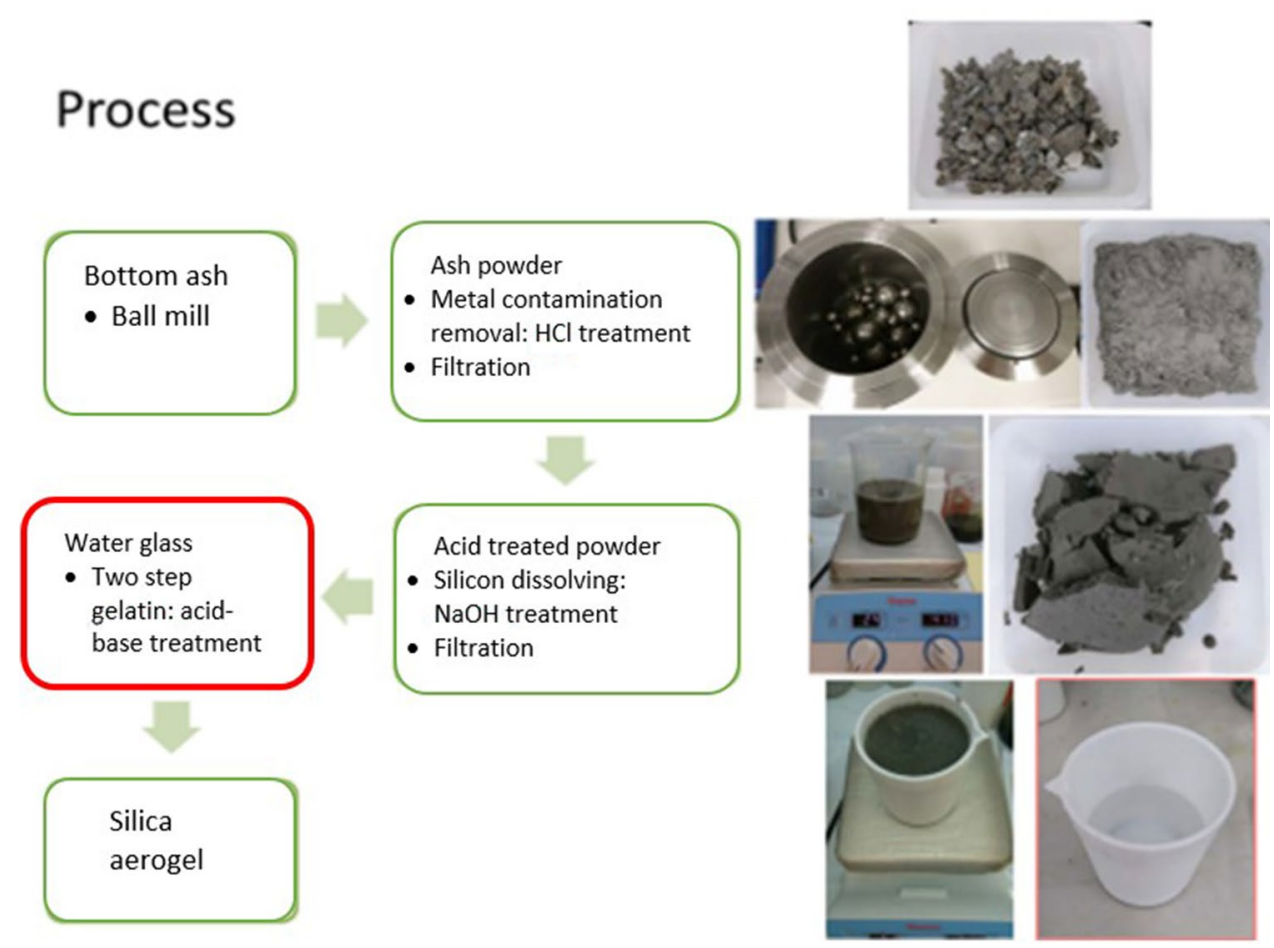
the fabricated aerogel products in different forms are shown in Fig. 2 including aerogel powder, aerogel granulate, and aerogel blanket with glass fiber reinforcement.

The first step was the production of sodium silicate or water glass solution. Firstly, the incineration ashes were ground by using a ball miller to reduce the particle size to below $300 \mu \mathrm{m}$ for efficient chemical treatment. Secondly, it underwent leaching process with $1 \mathrm{M}$ Hydrochloride $(\mathrm{HCl})$ solution for $3 \mathrm{~h}$ to remove the contaminated metal elements, such as iron. And the solid powders were then collected by vacuum filtration. Thirdly, silicon was extracted from the treated ashes by refluxing with 2-M sodium hydroxide solution for $24 \mathrm{~h}$ to form the water glass solution.

After the production of the water glass solution, the second step was the fabrication of silica aerogel. Firstly, the water glass solution was diluted to silica sol with a silicon content of around $6 \mathrm{wt} \%$ with deionized water. A total of 1-M $\mathrm{HCl}$ solution was added drop by drop under stirring until the $\mathrm{pH}$ value of $8 \sim 11$ was reached. The gelation of the solution was completed within $3 \sim 5 \mathrm{~min}$. The gel was then left for aging for $3 \mathrm{~h}$ at room temperature and followed by crushing into small pieces. The surface modification of the gel was done by adding isopropanol, n-Hexane, and trimethylsilyl chloride (TMCS) into the gel under stirring for $3 \mathrm{~h}$. The volume ratio of gel, isopropanol, and n-Hexane was kept at 10:3:6. The molar ratio of silica and TMCS was chosen to be 1:4. The gel after treatment could float on top of the liquid phase. Finally, the silica aerogel granulate was obtained by removing the liquid at the bottom and drying the gel at $50{ }^{\circ} \mathrm{C}$ for $1 \mathrm{~h}$ and at $150{ }^{\circ} \mathrm{C}$ for $1 \mathrm{~h}$ in an oven. The silica aerogel powder could be prepared by further grinding the silica aerogel granulate. Alternatively, after removing the bottom liquid, the silica aerogel blanket could be obtained by immersing glass fiber blanket into the gel for complete coating of the fiber with gel and followed by drying at $50{ }^{\circ} \mathrm{C}$ for $3 \mathrm{~h}$ and at $150{ }^{\circ} \mathrm{C}$ for $1 \mathrm{~h}$ in an oven.

The structure of the silica aerogel was characterized by $\mathrm{X}$-ray diffraction (XRD, D8-ADVANCE, Bruker, USA). The surface area of the silica aerogel powder was determined by nitrogen physisorption measurements with a Nova 2200e (Quantachrome, USA). The thermal gravimetric analysis
(TGA) test was performed by a TGA/DSC Simultaneous Thermal Analyzer (Mettler Toledo, Switzerland) to study the thermal stability of the aerogel. The specimen was heated from room temperature to $900{ }^{\circ} \mathrm{C}$ at a rate of $10{ }^{\circ} \mathrm{C} / \mathrm{min}$ in argon. The thermal conductivity was determined by a C-Therm TCi Thermal Conductivity Analyzer (C-Therm Technologies, Canada) using the modified transient plane source method under ambient conditions.

\section{Discussion}

The density of silica aerogel powder is measured to be around $0.08 \mathrm{~g} / \mathrm{ml}$ and its porosity is calculated to be $96.36 \%$. Its thermal conductivity is measured to be around $0.025 \mathrm{~W} /$ $\mathrm{mK}$. The surface area of the fabricated silica aerogel powder is $786 \mathrm{~m} 2 / \mathrm{g}$. The characterization shows the silica aerogel fabricated has comparable properties with the commercial silica aerogel (Aerogel Technologies 2021).

The XRD pattern of SA powder is shown in Fig. 3. The XRD result shows a broad peak between 20 and $30^{\circ}$ without any sharp peaks, which indicates that the SA powder is fabricated in amorphous structure (Khedkar et al. 2019).

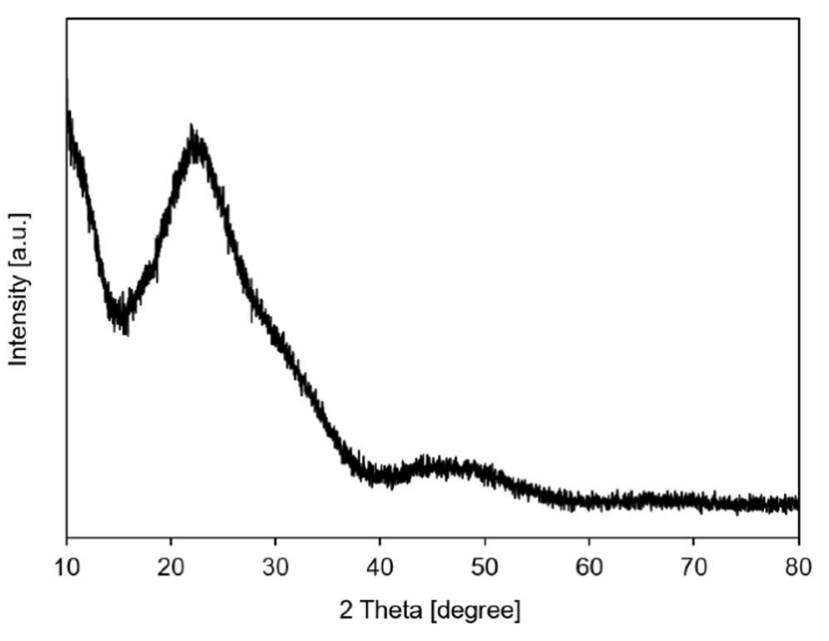

Fig. 3 XRD pattern of silica aerogel powder
Fig. 2 Aerogel product made from incineration ashes, aerogel powder (left), aerogel granulate (middle), and aerogel blanket (right)
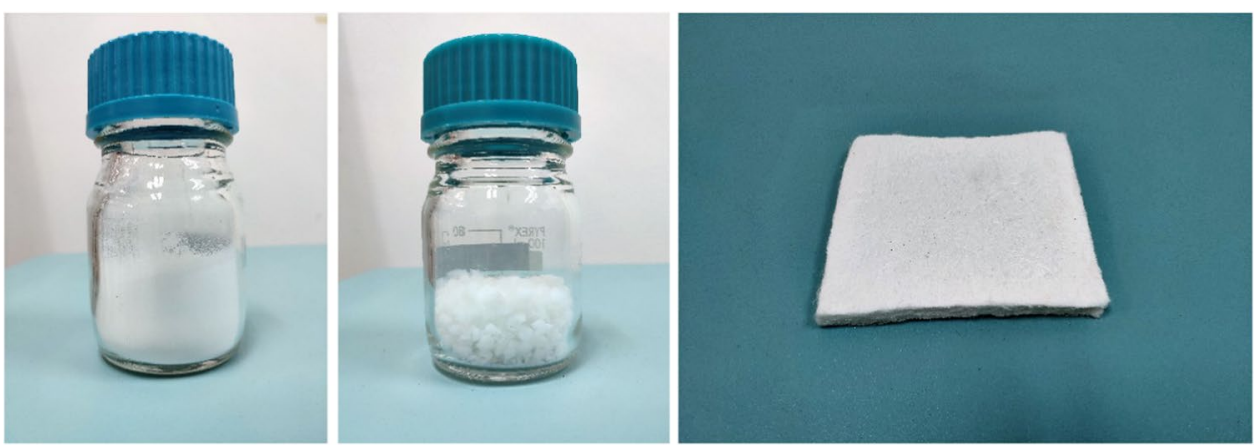
Thus, the safety of the SA powder can be assured with no or minimal chronic effects for application in building insulation (Nafisi et al. 2017).

A test-bedding of silica aerogel insulation has been done at Singapore Polytechnic Graduate Guild in order to under the insulation performance of silica aerogel, see Fig. 4. A silica aerogel blanket was sandwiched between two glass panels and installed outside the window. The temperatures were monitored and recorded through the temperature sensors installed, both inside and outside, at the surface of the insulation panels. The $24-\mathrm{h}$ data showed an up to $14.8^{\circ} \mathrm{C}$ reduction at the peak temperature of the day, indicating excellent insulation performance of the silica aerogel.

The developed technologies offered industrial supports to companies ranging from small-medium to large enterprises for producing high value products as well as recycling solid waste. A large company Y has many different activities during day to day operations. As a current practice, they have to incinerate their solid waste and ship all the ashes to a dumping site of Semakau Island. However, Semakau landfill is projected to reach its full capacity in 10-20 years time and there is a need for a sustainable solution in a long run. In this work, they collaborated with AMTC by providing incineration solid waste as raw materials, and at the same time, minimizing their incineration solid waste as land fill materials. A small medium enterprise company of $\mathrm{X}$ came in and found a potential opportunity to extend the economy by receiving such waste materials as an input material from the large company of $\mathrm{Y}$ in a recycling process to produce high value product such as silica aerogel materials. Through the Singapore Polytechnic's R\&D platform, an efficient recycling process was developed with the objective of transferring such technology to support and manage the upscaling production of the aerogel. Upon the success of this upscaling and test-bedding, the technology will be adopted by the company $\mathrm{X}$ for full commercialization.

This development does not only improve the low recycling rate of ash, but also find a useful alternative for this material. It is also able to prolong the lifespan of Semakau landfill, resonating with the government's initiative to reduce the waste sent to Semakau. In addition, the produced silica aerogel is a high-quality product which would solve multiple problems upon its fruition and be applied as thermal insulating materials (for refrigeration and construction use, see Fig. 4), acoustic barriers, absorbents, catalytic supports, and super capacitators.

Here, we have done a breakeven analysis to determine the point at which revenue received equals expenses for the production of silica aerogel from incineration ash business in Singapore. Figure 5 shows the components of revenue, fixed cost, and variable cost of practice. As can be seen in Fig. 6, the breakeven point is reached when treating $52,000 \mathrm{~kg}$ ashes per year. This represents about $3 \%$ of the incineration ash generated in Singapore per day. The low volume of breakeven point makes the recycling business feasible.

\section{Conclusion}

The elimination of solid waste through the superior and efficient design of materials, products, systems, and business models is part of a circular economy, which is
Fig. 4 Application of silica aerogel insulation window (left), and indoor temperature reduction by $14.8{ }^{\circ} \mathrm{C}$ (right)

Fig. 5 Components of revenue, fixed cost, and variable cost
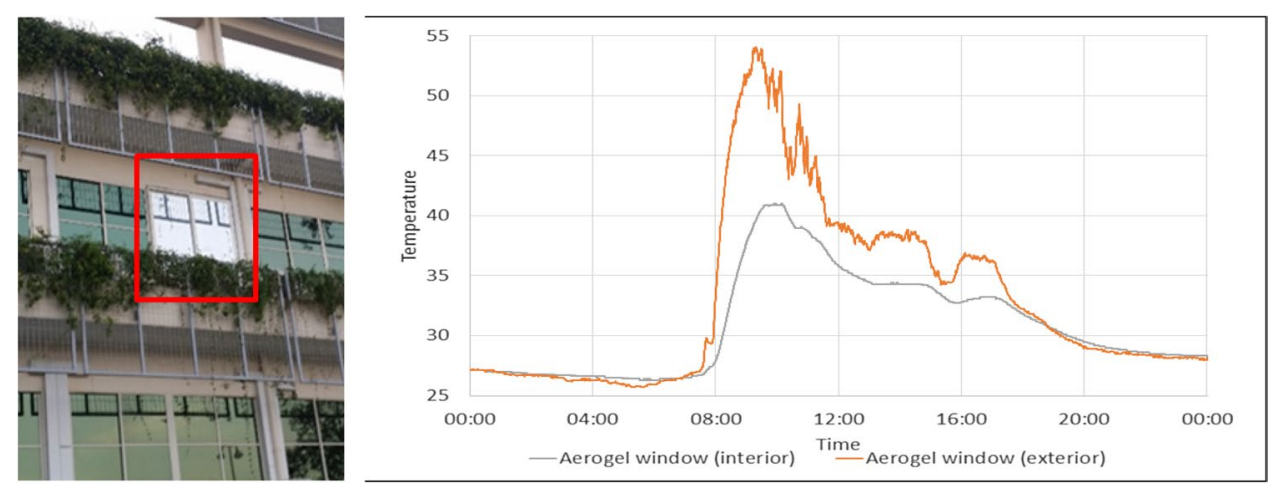

Fixed Cost

\begin{tabular}{|l|}
\hline Manpower \\
\hline Factory rental \\
\hline Machines depreciation (5 yrs) \\
\hline Setup cost depreciation \\
\hline Other overhead \\
\hline
\end{tabular}

Variable cost

\begin{tabular}{|l|}
\hline Raw materials and chemicals \\
\hline Disposal of liquid waste \\
\hline Utility \\
\hline Transportation \\
\hline
\end{tabular}




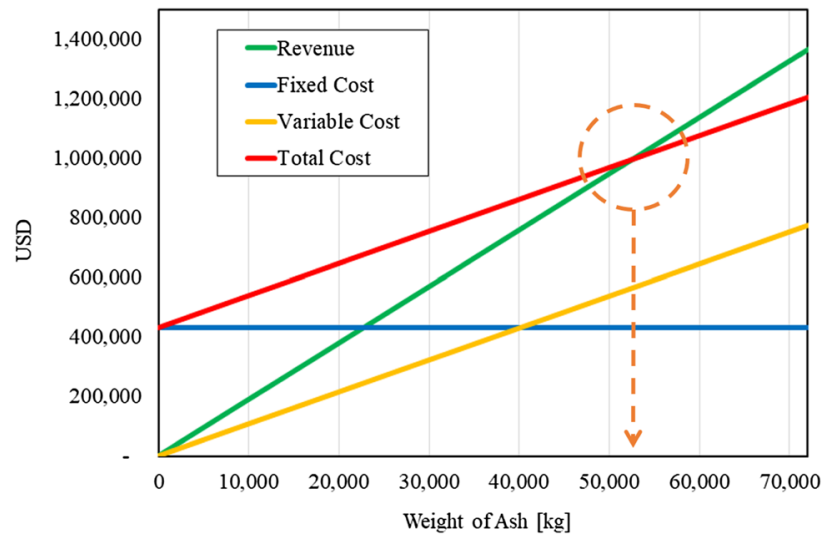

Fig. 6 Financial analysis

restorative or regenerative by intention and design. The application of the products can be sustainable and supports future circular economy.

Silica aerogel material has many applications and it can be modified to meet a number of specific purposes required by an industry. Granular aerogel can be mixed to develop a green building material with unique characteristics. The results showed that the developed have a great potential for an application in green and sustainable building.

Due to shortage of natural resource, the role of academic and research has shifted into a new landscape where the $\mathrm{R}$ and $\mathrm{D}$ platform had more focus on industrial engagement to offer industrial supports to companies ranging from small-medium to large enterprises.

Author contribution H Djati Utomo: contribute as a project coordinator, reviewer, and presenter during CESE2020.

XD Li: contribute in writing up some technical sections.

ETJ, Ng: contribute in writing up some internal transformation of our institution.

Funding Singapore Polytechnic-Technology Harvesting Fund (J720) for the design of the study and collection, analysis, and interpretation of data.

Data availability The datasets used and/or analyzed during the current study are available from the corresponding author on reasonable request.

\section{Declarations}

Ethics approval and consent to participate Not applicable.

Consent for publication Not Applicable.

Competing interests The authors declare no competing interests.

\section{References}

Aerogel Technologies (2021) Available online: http://www.buyaerogel. $\mathrm{com} /[1 \mathrm{Dec} 2021]$

CNA (2018) Gwyneth Teo, ChannelNewsAsia. Singapore Polytechnic, waste management recycling association to work together on innovative solutions for waste industry. Jun 2018. Available Online: https://www.channelnewsasia.com/news/singapore/singaporepolytechnic-waste-management-recycling-association-to-10362 462 [27 Sep 2020]

de Sousa Jabbour LAB, Jabbour CJC, Godinho Filho M et al (2018) Industry 4.0 and the circular economy: a proposed research agenda and original roadmap for sustainable operations. Ann Oper Res 270:273-286. https://doi.org/10.1007/s10479-018-2772-8

Gao T, Jelle BP, Gustavsen A, Jacobsen S (2014) Aerogelincorporated concrete: an experimental study, construction and building materials, 52 (2014), pp. 130-136

Hamilton C (2003) University technology transfer and economic development: proposed cooperative economic development agreements under the Bayh-Dole Act, 36 J. Marshall L. Rev. 397 (2003). Available online: https://files.eric.ed.gov/fulltext/ED577439.pdf

IES (2014) The Institution of Engineers, Singapore, IES Prestigious Engineering Achievement Awards. 2014. Available online: https:// www.ies.org.sg/ccms.r?pageid=10113\&TenID=IES [26 Sep 2020]

IPCC (2008) Who are they and why do their climate reports matter? 16 Jul 2008. Unions of Concerned Scientists. Available Online: https://www.ucsusa.org/resources/ipcc-who-are-they\#: :text= history\%20and $\% 20$ mission-, The\%20Intergovernmental\%20Pan el\%20on\%20Climate $\% 20$ Change $\% 20$ (IPCC)\%20was\%20establis hed\%20in,of\%20the\%20risk\%20of\%20human\%2D [25 Sep 2020]

Kow K-W et al (2014) From bamboo leaf to aerogel: preparation of water glass as a precursor. J Non Cryst Solids 386:76-84

Khedkar MV, Somvanshi SB, Humbe AV et al (2019) Surface modified sodium silicate based superhydrophobic silica aerogels prepared via ambient pressure drying process. J Non Cryst Solids 511:140-146

Lee K, Choe Y, Kim YH, Lee JK, Hwang H (2018) Fabrication of silica aerogel composite blankets from an aqueous silica aerogel slurry. Ceram Int 44:2204-2208

Lu Y, Li X, Yin X et al (2018) Silica aerogel as super thermal and acoustic insulation materials. J Environ Prot 9:295-308

Michelinia G, Moraesa Renato N, Cunhab Renata N, Costaa Janaina M. H, Omettoa Aldo R (2017) From linear to circular economy: PSS conducting the transition. The 9th CIRP IPSS conference: circular perspectives on product/service-systems. Procedia CIRP 64:2-6

MOE (2016) List of sector coordinators, Ministry of Education. 2016. Available Online: https://www.moe.gov.sg/docs/default-source/ document/media/press/2016/annex-b---press-release-on-skillsfutu re-and-lifelong-learning.pdf [26 Sep 2020]

Nafisi S, Schäfer-Korting M, Maibach HI (2017) Measuring silica nanoparticles in the skin. In: Humbert P, Fanian F, Maibach $\mathrm{H}$, Agache P (eds) Agache's Measuring the Skin. Springer, Cham, pp 1141-1164

Nanostart Asia Pacific (2012) New investment in Singapore, 23 May 2012. Available online: https://www.nanowerk.com/news/ newsid=25336.php

NASA (2012) NASA's technology transfer activities. 12 Nov 2012. Available online: https://www.nasa.gov/open/technology-trans fer.html

NEA (2020) Singapore's inaugural zero waste masterplan charts Singapore's path towards a zero waste nation. Published by Ministry of the Environment and Water Resources, National Environment Agency. Available Online: https://www.towardszerowaste.gov.sg/ images/zero-waste-masterplan.pdf [25 Sep 2020] 
Pan Y, He S, Cheng X et al (2017) A fast synthesis of silica aerogel powders-based on water glass via ambient drying. J Sol-Gel Sci Technol 82:594-601

Sembcorp (2015) Green wave environmental care competition. Sembcorp Marine Ltd. 2015. Available online: https://www.sembm arine.com/greenwave/awards-result/2015 [26 Sep 2020]

Singapore 21 Committee (1999) Singapore 21: Together, we make the difference (p. 7). Singapore 21 Committee

Singapore Polytechnic (2014) Available Online: https://www.sp.edu.sg/ $\mathrm{sp} /$ news/Singapore-Polytechnic-launches-first-of-its-kind-comme morative-green-book [25 Sep 2020]

Singapore Polytechnic (2018) Speech by MOS Zaqy Mohamad at the Singapore Polytechnic's School of Architecture and the built environment 60th anniversary dinner, 12 Oct 2018. Available online: https://www.mnd.gov.sg/newsroom/speeches/view/speech-bymos-zaqy-mohamad-at-the-singapore-polytechnic-s-school-ofarchitecture-and-the-built-environment-60th-anniversary-dinner [26 Sep 2020]
Singapore Polytehnic (2020) Research. 2020. Available online: https:// www.sp.edu.sg/abe/industry-/research

The Strait Times (2017) Beh Swan Gin for The Straits Times, Singapore's long game in innovation. Published 23 AUG 2017, 5:00 AM SGT. Available online: https://www.straitstimes.com/opini on/singapores-long-game-in-innovation

The Strait Times (2019) Singapore Polytechnic team turns ash from waste into building material, sound barrier, water decontaminant. Timothy Goh, The Straits Times. 5 Dec 2019. Available online: https://www.straitstimes.com/singapore/environment/singaporepolytechnic-team-turns-ash-from-waste-into-building-materialsound [27 Sep 2020]

Publisher's note Springer Nature remains neutral with regard to jurisdictional claims in published maps and institutional affiliations. 